\title{
IUGS Financial Situation and Statement
}

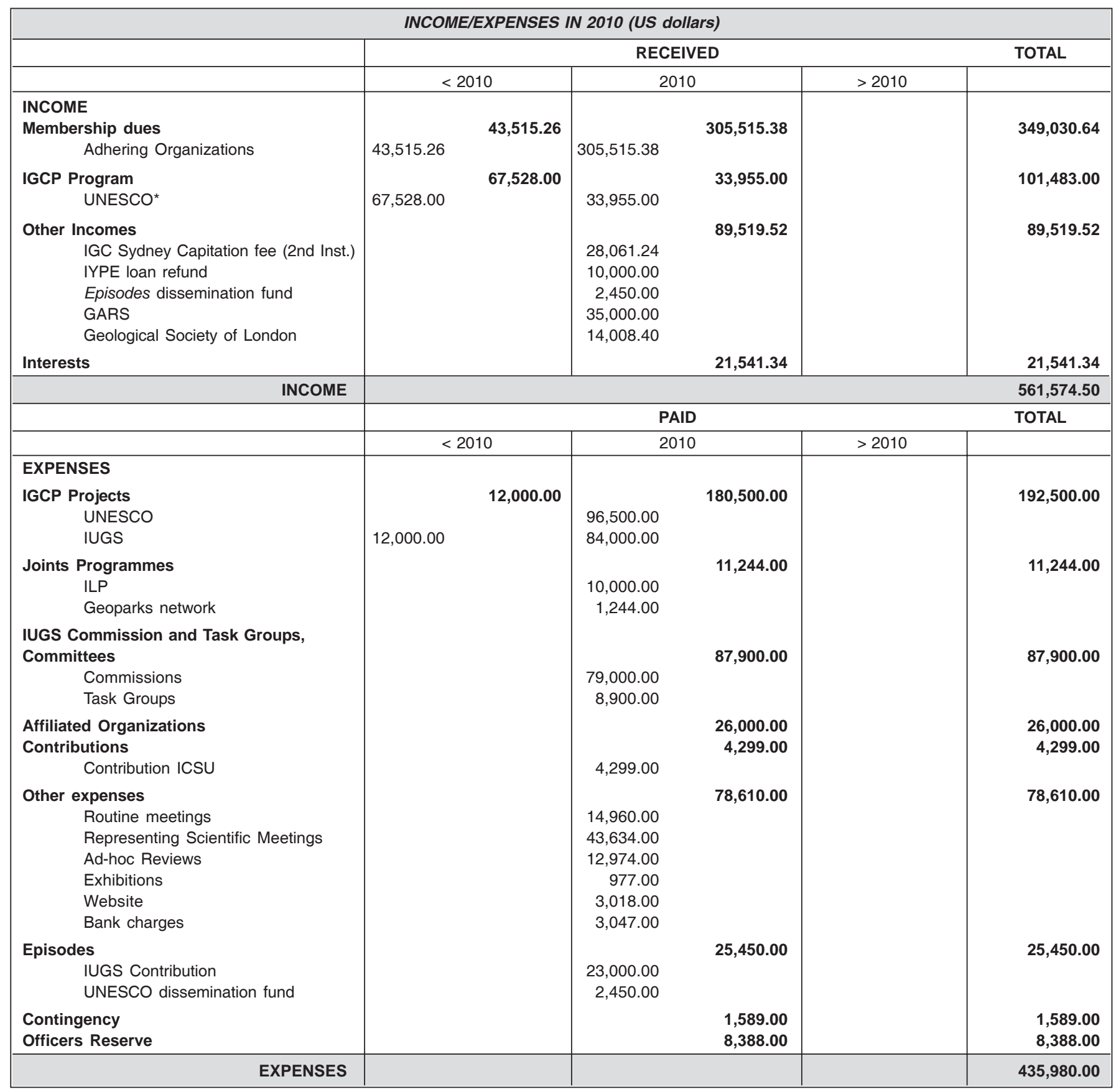


IUGS Financial Situation on December $31^{\text {st }}, 2010$

\begin{tabular}{|l|rr|}
\hline Income 2010 & USD & $561,574.50$ \\
\hline Expenses 2010 & USD & $435,980.00$ \\
\hline Balance & USD & $+125,594.50$ \\
\hline
\end{tabular}

\section{Comments}

- Bank and financial interests were: 21,541.34 USD

- IUGS recovered the amount of 43,515.26 USD as fees for previous years.

- Total allocation for IGCP 2010 was 180,500 USD compared to 189,500 USD in 2009 and 166,000 USD in 2008. During 2010 IUGS received from UNESCO 67,528 USD for IGCP 2009 and 34,000 USD for IGCP 2010.

- IUGS has still to receive from UNESCO by 31st March 2011: 19,000 USD for IGCP 2010.

IUGS expenditures often do not reflect the real costs. For example, the IUGS Secretariat, partially sponsored by IUGS, is graciously hosted by the United States Geological Survey in Reston (Virginia, USA). The same holds true for Episodes as our annual contribution for editing, layout, printing and distribution, covers only a part of the actual costs incurred by the Geological Society of India, Bangalore which hosts the journal. The costs related to IUGS meetings are covered, at least in part, by the countries hosting such meetings and for a very substantial part by the parent organisations of the Bureau members (Secretary-General and Treasurer and their supporting staff) which cover salary and all their travel costs. These forms of support save IUGS a considerable amount per year. IUGS is extremely grateful to the Canadian, Indian, Italian, and U.S.A. governments for this generous support that enables the Union to invest significantly more in science development than would be otherwise possible.

\section{IUGS Financial Statement for 2010}

\section{Income}

\section{Adhering Organizations}

- Total 121 Adhering Organizations: 87 active (7 pending), 34 inactive

- Guyana and Korea North (PDR) - both Category 1 - were reinstated into Active Status

- India upgraded from Category 5 to Category 7

Situation of Adhering Organizations:

\begin{tabular}{|c|c|c|}
\hline ACTIVE & INACTIVE & TOTAL \\
\hline 87 & 34 & 121 \\
$(94$ in 2009$)$ & $(27$ in 2009$)$ & $(121$ in 2009$)$ \\
$(94$ in 2008$)$ & $(25$ in 2008$)$ & $(119$ in 2008$)$ \\
$(88$ in 2007$)$ & $(30$ in 2007$)$ & $(118$ in 2007$)$ \\
$(83$ in 2006$)$ & $(35$ in 2006$)$ & $(118$ in 2006$)$ \\
$(77$ in 2005$)$ & $(40$ in 2005$)$ & $(117$ in 2005$)$ \\
$(79$ in 2004$)$ & $(37$ in 2004$)$ & $(116$ in 2004$)$ \\
\hline
\end{tabular}

\section{Other incomes}

- IUGS received from the Organizing Committee of the $34^{\text {th }}$ IGC, Brisbane a contribution of USD 28,061.24 towards payment of capitation fee.

- IUGS received from IYPE 10,000 USD as reimbursement of earlier loan.

- IUGS received from the Geological Society of London the amount of USD 14,008.28 for the publication of IUGS-related Special Volumes.

- Interests: USD 21,541.34.

\section{Expenses}

\section{IGCP}

- Total expenses for IGCP were USD 192,500 including 12,000 USD for IGCP Projects 2009.

\section{Joint Programmes}

- USD 11,244 were allocated to the following Joint Programmes: Scientific Commission on the Lithosphere (ILP) and Geoparks Network.

Commissions, Task Groups, Committees, Affiliated Organizations

- USD 113,900 were allocated to this group of IUGS bodies. The largest amount was allocated to the International Commission on Stratigraphy - ICS (USD 50,000).

\section{IUGS Contributions}

- IUGS contributed USD 4,299 to ICSU for 2010.

Other Expenses

- USD 14,960 for routine meetings.

- USD 43,634 for representative meetings.

- USD 23,000 as a contribution toward the printing of Episodes

- USD 3,047 for Bank charges.

- USD 1,589 for contingency (promotional items, postage, new business cards, stamps, DHL, etc). 